Illinois State University

ISU ReD: Research and eData

Theses and Dissertations

7-2-2018

\title{
Using Context Specific Measures Of Maximizing Tendency To Reduce Inconsistency In Findings
}

Thomas Holzhauer

Illinois State University, teholzh@ilstu.edu

Follow this and additional works at: https://ir.library.illinoisstate.edu/etd

Part of the Quantitative Psychology Commons

\section{Recommended Citation}

Holzhauer, Thomas, "Using Context Specific Measures Of Maximizing Tendency To Reduce Inconsistency In Findings" (2018). Theses and Dissertations. 913.

https://ir.library.illinoisstate.edu/etd/913

This Thesis is brought to you for free and open access by ISU ReD: Research and eData. It has been accepted for inclusion in Theses and Dissertations by an authorized administrator of ISU ReD: Research and eData. For more information, please contact ISUReD@ilstu.edu. 


\section{USING CONTEXT SPECIFIC MEASURES OF MAXIMIZING TENDENCY TO REDUCE INCONSISTENCY IN FINDINGS}

\section{THOMAS HOLZHAUER}

\section{Pages}

The relation between maximizing tendency, the tendency to search for alternatives to make the highest quality decision, and its theorized outcome, regret, has mixed support in previous maximizing tendency literature. In the current study, it was hypothesized that measuring maximizing tendency in different contexts, as opposed to measuring maximizing tendency globally, could reduce this inconsistency. This hypothesis was tested by administering measures of maximizing tendency from different contexts and maximizing tendency without context and using the results in hypothesized models. The models were tested using confirmatory factor analysis, structural equation modeling, and path analysis. Results showed that using context specific measures of maximizing tendency did not predict regret better and instead showed that using measures of maximizing tendency without context led to models predicting regret with marginally good fit. Exploratory analyses, lastly, revealed that separating maximizing tendency into its components may have practical implications for future studies attempting to reduce inconsistency in the maximizing tendency literature.

KEYWORDS: Maximizing Tendency, Global vs. Specific, Confirmatory Factor Analysis, Structural Equation Modeling, Path Analysis 


\section{USING CONTEXT SPECIFIC MEASURES OF MAXIMIZING TENDENCY TO REDUCE INCONSISTENCY IN FINDINGS}

THOMAS HOLZHAUER

A Thesis Submitted in Partial Fulfillment of the Requirements for the Degree of

\section{MASTER OF SCIENCE}

Department of Psychology

ILLINOIS STATE UNIVERSITY 
Copyright 2018 Thomas Holzhauer 


\section{USING CONTEXT SPECIFIC MEASURES OF MAXIMIZING TENDENCY TO REDUCE INCONSISTENCY IN FINDINGS}

THOMAS HOLZHAUER

COMMITTEE MEMBERS:

Matthew Hesson-McInnis, Chair

Julie Campbell 


\section{ACKNOWLEDGMENTS}

I would like to thank the members of my thesis committee, Dr. Matthew Hesson-McInnis and Dr. Julie Campbell, for their input on creating test measures, administering those measures, and the models that would use the results and for help with proofreading drafts of this thesis. I would also like to thank Dr. Jeff Khan for help with the development of the theory that context specific measures of maximizing tendency could be beneficial to consistent findings that is used throughout this thesis. Lastly, I would like to think friends and family for proofreading early drafts of this thesis.

T.H. 


\section{CONTENTS}

Page

AKNOWLEDGEMENTS

TABLES

FIGURES

CHAPTER I: INTRODUCTION

CHAPTER II: REVIEW OF LITERATURE

CHAPTER III: PILOT STUDY 13

$\begin{array}{ll}\text { Participants } & 13\end{array}$

$\begin{array}{ll}\text { Measures } & 13\end{array}$

$\begin{array}{ll}\text { Procedure } & 14\end{array}$

CHAPTER IV: METHODS 15

$\begin{array}{ll}\text { Participants } & 15\end{array}$

$\begin{array}{ll}\text { Measures } & 15\end{array}$

$\begin{array}{ll}\text { Procedure } & 16\end{array}$

$\begin{array}{ll}\text { Data Analysis } & 17\end{array}$

$\begin{array}{ll}\text { CHAPTER V: RESULTS } & 19\end{array}$

$\begin{array}{ll}\text { Descriptive Statistics } & 19\end{array}$

$\begin{array}{ll}\text { Reliability } & 24\end{array}$

$\begin{array}{ll}\text { Exploratory Factor Analyses } & 24\end{array}$

Confirmatory Factor Analyses 30

Structural Equation Modeling and Path Analyses 33 
Exploratory Analyses

CHAPTER VI: DISCUSSION

Limitations

Future Directions 


\section{TABLES}

Table

Page

1. Correlations between the items of the Adapted Relational Maximizing Scale

2. Correlations between the items of the Maximizing in Career Decisions Scale

3. Correlations between the items of the Maximizing in Consumer Decisions Scale

4. Correlations between the items of the Global Maximizing Scale

5. Correlations between the items of the Regret Scale

6. The loadings for the principal component analysis of the RMS items

7. The loadings for the principal component analysis of the Maximizing in Career Decisions Scale items

8. The loadings for the principal component analysis of the Maximizing in Consumer Decisions Scale items

9. The loadings for the principal component analysis of the Global Maximizing Scale items

10. Correlations between the item parcels created from the principal component analyses

11. Standardized estimates for the lambdas and theta-deltas for the confirmatory factor analysis of the three-factor model

12. Parameter estimates for the three-factor model using the high standards items 


\section{FIGURES}

Figure

Page

1. The hypothesized model that is tested with confirmatory factor analysis $\quad 8$

2. The hypothesized model that is tested through structural equation modeling 9

3. Model that is tested through structural equation modeling in Hypothesis 4

4. Model that is tested through structural equation modeling in Hypothesis 5

5. The model for hypothesis three tested with path analysis 34

6. The model tested for Hypotheses 4 and 5 with all paths in the model 36

7. The model testing Hypothesis 4 using only the high standard measures of the maximizing scales 


\section{CHAPTER I: INTRODUCTION}

Maximizing tendency can be defined as the need of an individual to search for alternative options when making a decision to make the best decision possible (Schwartz, 2002). Through exploratory factor analysis, the definition of maximizing tendency originally created by Schwartz (2002) was found to have three components: decision difficulty, alternative search, and high standards (Nenkov et al., 2008). The dubbing of the two factors, alternative search and high standards, is intuitive as these terms are derived from the definition of maximizing tendency with the individual need to search for alternative options and to maximize the positive outcomes of the decision. The dubbing of the decision difficulty factor, although less intuitive, also makes sense as a decision becomes more difficult when more choices are present. The Maximization Scale (MS) developed by Schwartz (2002) contains these three factors.

Maximizing tendency measured using the MS has been found to be positively correlated with regret. The relation between maximizing tendency and regret has been supported with replication of the positive correlation between maximizing tendency and regret through studies utilizing the MS (Purvis et al., 2011). The maximizing tendency of an individual is also found to be positively correlated with negative outcomes, such as feelings of regret and depression (Bruine de Bruin et al., 2016). These results support that interventions to decrease high maximizing tendencies in individuals could be beneficial and decrease symptoms of depression later in life. Other studies, however, have found maximizing tendency to be positively correlated with positive outcomes such as higher intrinsic motivation and higher self-efficacy (Lia, 2010). These results show inconsistency in the literature of maximizing tendency. A possible reason for this inconsistency could be the use of different scales when measuring maximizing tendency. 
The scale used by Lia (2010) did not include items related to decision difficulty, one of the three components of maximizing tendency in the definition of maximizing tendency by Schwartz (2002). The lack of these decision difficulty items may have led to the correlations between positive outcomes and maximizing tendency. Thus, the correlates of maximizing tendency may differ depending on the type of measurement scale used.

With inconsistent findings on maximizing tendency and the correlates of maximizing tendency, further research could better define maximizing tendency to increase consistency in findings. A method that has been used in previous literature to increase this consistency is that of creating new scales measuring maximizing tendency. Maximizing tendency can also be measured using the Maximizing Tendency Scale (MTS) developed by Diab and colleagues (2008). Maximizing tendency measured using this scale has also been found to be positively correlated with regret (Diab et al., 2008), which supports the claim that high maximizing tendency leads to greater regret, which in turn leads to lower subjective well-being. Inconsistencies, however, are also present when measuring maximizing tendency with the MTS. Kokkoris (2016) found differences between the MS and the MTS; Kokkoris (2016) found that maximizing tendency was negatively correlated with satisfaction with life when measured with the MS and was not significantly correlated with satisfaction with life when measured with the MTS. Furthermore, Kokkoris (2016) found that maximizing tendency was not significantly correlated with eudemonic well-being, or well-being based on an individual's feelings of meaning in life, when measured with the MS and was positively correlated with eudemonic wellbeing when measured with the MTS. These findings lead to greater inconsistency with maximizing tendency measured using the MTS leading to more positive outcomes. 
A possible reason for this inconsistency is that the MS and MTS do not appear to measure the same components of the maximizing tendency construct. Weinhardt and colleagues (2012) found that the MTS does not include items related to decision difficulty, a component of the MS, and this difference may be responsible for the inconsistencies in the literature of maximizing tendency. From here, it can be argued that the MTS changed the original definition of maximizing tendency to create better estimates of maximizing tendency. Changing the definition, however, may not have led to better estimates of maximizing tendency based on the inconsistencies that are still present with the use of different maximizing tendency scales. A different method, therefore, should be utilized to create better estimates of maximizing tendency while providing consistent results that can support the reliability of the estimates.

Instead of changing the core elements of the definition of maximizing tendency created by Schwartz (2002), the current study proposes to change the scope of maximizing tendency based on context. According to Cheek \& Schwartz (2016), measuring maximizing tendency in specific domains may be beneficial in estimating maximizing tendency in the contexts of these specific domains. With better estimates of maximizing tendency, more consistent findings may be acquired when correlating maximizing tendency with negative outcomes of regret and positive outcomes of high self-efficacy. Better estimates of maximizing tendency, however, may not be achieved if the tendency to maximize is universal to all situations making maximizing tendency consistent across all contexts. However, with the current study it is argued that maximizing tendency differs based on context as context specific measures of maximizing tendency have yielded more consistent results than those yielded by measures of maximizing tendency that are not dependent on specific contexts. 


\section{CHAPTER II: REVIEW OF LITERATURE}

Maximizing tendency has been measured in several specific domains: romantic relationships, career satisfaction, and consumer decisions (Mikkelson \& Pauley, 2013; Iyengar et al., 2006; Carter \& Gilovich, 2010). Measuring maximizing tendency based on these specific domains may predict maximizing tendency in these domains better. If this claim is supported, it may indicate that maximizing tendency is more domain specific and differs between contexts. With this information, interventions to decrease maximizing tendency based on context could be performed with more effective results than interventions to decrease maximizing tendency regardless of context.

Previous studies have found maximizing tendency to be negatively correlated with commitment, investment, and satisfaction in both romantic and non-romantic relationships (Mikkelson \& Pauley, 2013; Newman et al., 2017). These results were found using the Relational Maximizing Scale (RMS) developed by Mikkelson \& Pauley (2013) and an adapted version of the same scale developed by Newman and colleagues (2017). The RMS was adapted from the MS developed by Schwartz (2002) by changing the items to fit the context of interpersonal relationships (Mikkelson \& Pauley, 2013). With these results, it is supported that investigating maximizing tendency based on the context of interpersonal relationships yielded significant results coherent with those of previous findings. The findings of Mikkelson \& Pauley (2013) also support that investigating maximizing tendency in different contexts may also yield significant and consistent results. Consistent results were found when the study was followed by Newman and colleagues (2017) using non-romantic, interpersonal relationships as opposed to romantic, interpersonal relationships. These findings support that domain specific measurements 
of maximizing tendency may have more precise estimates of maximizing tendency. Such measurements may find conclusive results that could be contrary to those of the current literature of maximizing tendency as well.

In addition to maximizing tendency in interpersonal relationships, other domain specific measures of maximizing tendency have been present in the maximizing tendency literature. The context of career decisions can be seen in a study by Iyengar and colleagues (2006) where it was found that maximizing tendency was correlated with lower job satisfaction. These results led to growing research on maximizing tendency in the area of career decisions. Another study by Giacopelli and colleagues (2013) found that maximizing tendency, when measured using the MS developed by Schwartz and colleagues (2002), was negatively correlated with both job satisfaction and ability to proficiently perform job duties. These results support investigating how career decisions are affected by regret due to maximizing tendency. More specific measurements of maximizing based on the context of career decisions could aid this investigating by providing more precise estimates of regret in the workplace and thus more precise estimates of both job satisfaction and proficiency in workplace tasks.

Another domain specific measure of maximizing tendency, the context of consumer decisions, can be identified in previous research in the maximizing tendency literature investigating this domain specific measure of maximizing tendency. Chowdhury and colleagues (2009) indicated different levels of maximizing tendency leading to differences in time searching while shopping, pressure felt from time while shopping, and probability of changing decisions while shopping. These results support that differences exist between those with different levels of maximizing tendency in the context of shopping, and this context should be investigated 
further when focusing on domain specific measures of maximizing tendency. Lia (2011) took this context further by looking at the outcomes of maximizing tendency in this context. Lia (2011) found that higher maximizing tendencies in individuals led to less consumer loyalty towards cable providers. These findings can be generalized to predict that maximizing tendency would lead to less consumer loyalty towards other providers of goods and services. If this generalization is supported, businesses could benefit from better estimates of maximizing tendency that could allow further insight on how maximizing tendency affects consumer decisions for their businesses. From here, businesses could identify how maximizing tendency could be reduced to improve customer loyalty of individuals with high maximizing tendencies.

Lastly, measuring maximizing tendency without context has led to lack of consistency in the maximizing tendency literature for global measures of maximizing tendency as seen by the results of the studies by Lai (2010) and Kokkoris (2016). In both of these studies, a global measure of maximizing tendency was utilized meaning the measure did not narrow the scope of the maximizing tendency to be domain specific (Lai, 2010; Kokkoris, 2016). Therefore, the current study investigates global maximizing tendency and how it compares to domain specific measures of maximizing tendency. Due to inconsistencies, global maximizing tendency is predicted to be less accurate than the three measures of maximizing tendency based on context in predicting overall maximizing tendency. If domain specific maximizing tendency is found to be a better predictor, global maximizing tendency can have less emphasis in future studies on maximizing tendency allowing for less inconsistent findings in these future studies.

The current study aims to determine the underlying stability of maximizing tendency, based on Schwartz's (2002) definition of maximizing tendency. Maximizing tendency could be 
consistent across contexts or it could differ when based in different contexts. First, the study uses a confirmatory factor analyses to determine if the items measuring maximizing tendency based on context and maximizing tendency without context fit a four-factor model or a single factor model. The four-factor model supports that the measures of maximizing tendency in different contexts without context can be used to account for different latent constructs. With support of the four-factor model, it is also supported that maximizing tendency differs based on context or lack of context and this difference should be investigated further. The four-factor model being tested can be found under Figure 1. The single-factor model, in contrast, supports that the items all account for a single latent construct, and support of this model could support that maximizing tendency does not differ based on context or lack of context. With these analyses, the current study tests the following competing hypotheses:

H1: The items measuring maximizing tendency in the context of interpersonal relationships, the context of career decisions, the context of consumer decisions, and without context will fit a four-factor model.

$\mathrm{H} 2$ : The items measuring maximizing tendency in the context of interpersonal relationships, the context of career decisions, the context of consumer decisions, and without context will fit a single-factor model. 


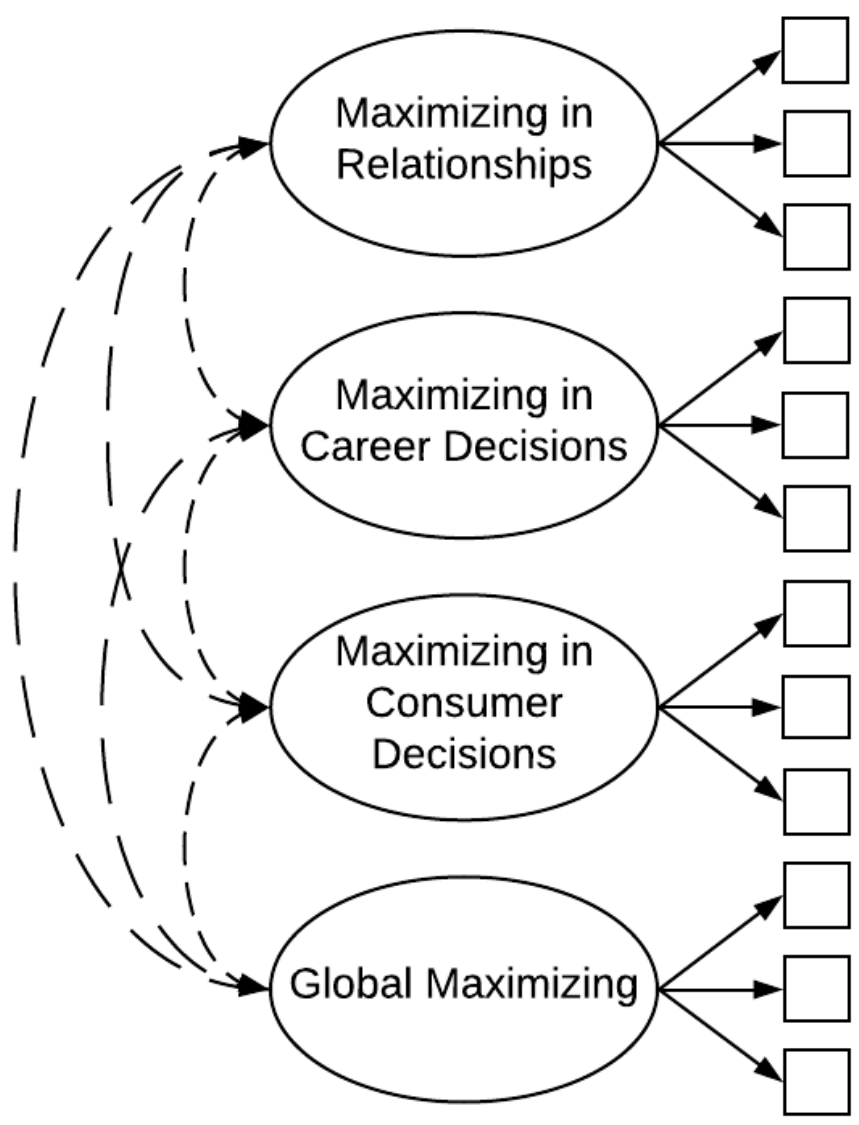

Figure 1. The hypothesized model that is tested with confirmatory factor analysis. It is hypothesized that the items will fit a four-factor model.

Based on the consistency of findings that use context specific measures of maximizing tendency, it is hypothesized that Hypothesis 1 will be supported, and Hypothesis 2 will not be supported. The next analysis in the current study uses structural equation modeling to determine the fit of a model with maximizing tendency based on specific contexts predicting global 
maximizing tendency. This model, if supported, indicates that the context specific measures of maximizing tendency account for overall maximizing tendency as opposed to a latent construct unrelated to maximizing tendency. The model that is tested using structural equation modeling can be found under Figure 2. The current study tests the following hypothesis:

H3: A model with maximizing tendency based on specific contexts predicting global maximizing tendency will have adequate fit.

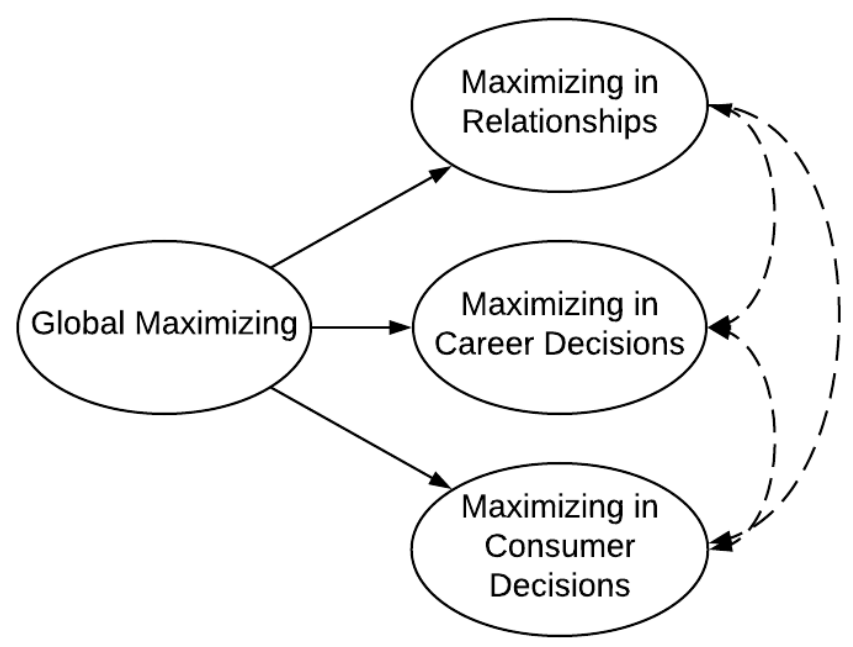

Figure 2. The hypothesized model that is tested through structural equation modeling. Components for each of the latent variables are not pictured. 
The next analysis in the current study determines the role of regret in the model. Two more structural equation modeling analyses are performed to determine which paths from the different measures of maximizing tendency towards regret are significant. The model with significant paths between the context specific measures of maximizing tendency and regret, if adequate fit is found, can be used to support that context specific measures of maximizing tendency are better estimates for maximizing tendency than global maximizing tendency when relating the construct of maximizing tendency with regret. The model with significant paths between global maximizing tendency and regret, if adequate fit is found, can be used to support that global measures of maximizing tendency are better estimates for maximizing tendency than context specific measures when relating the construct of maximizing tendency with regret. The models that are tested for Hypothesis 4 and the Hypothesis 5 can be found under Figure 3 and Figure 4 respectively. The current study tests the following competing hypotheses:

H4: A model with significant paths from the context specific measures of maximizing tendency toward regret and insignificant paths from the global measure of maximizing tendency toward regret will have adequate fit.

H5: A model with a significant path from the global measure of maximizing tendency toward regret and insignificant paths from the context specific measures of maximizing tendency towards regret will has adequate fit. 


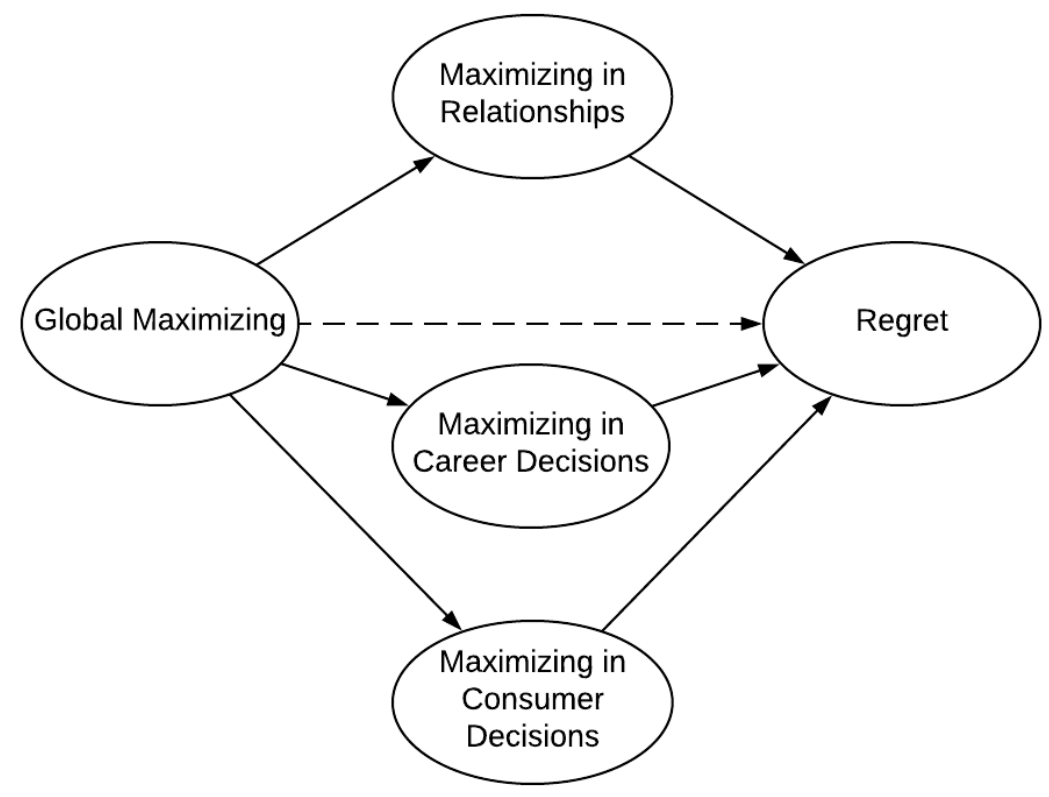

Figure 3. Model that is tested through structural equation modeling in Hypothesis 4.

Components for each latent variable are not pictured. Solid lines indicate significant paths while dashed lines indicate non-significant paths. 


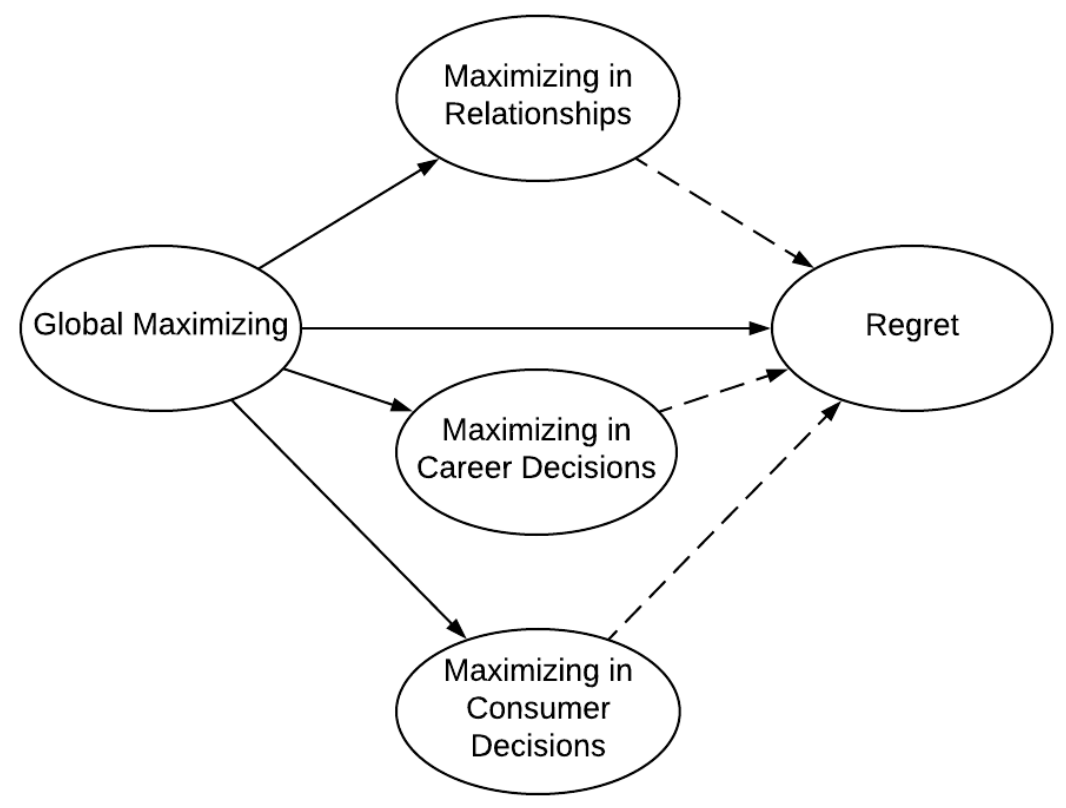

Figure 4. Model that is tested through structural equation modeling in Hypothesis 5.

Components for each latent variable are not pictured. Solid lines indicate significant paths while dashed lines indicate non-significant paths. 


\section{CHAPTER III: PILOT STUDY}

A pilot study was conducted to create measures of maximizing tendency in the contexts of career decisions and consumer decisions, and a global maximizing tendency scale without context. These three scales were adapted from the adapted RMS. For these new scales, words related to friendship in the adapted RMS were changed to fit the respective contexts.

\section{Participants}

A sample of 480 MTurk workers was given the test items for the pilot study. This sample was determined because including 10 participants per item is established as a standard for scale construction, and 48 items were tested (Bentler \& Chou, 1987). Participants were not targeted based on demographics of gender or ethnicity and were over the age of 18 . This limit on age was chosen as MTurk workers must be at least 18 years of age. Demographic questions were presented in order to determine if the sample avoided targeting based on gender, ethnicity, or age.

\section{Measures}

Maximizing tendency in career decisions were adapted from the items of the adapted RMS adapted by Newman and colleagues (2017). This 16-item scale was developed by replacing words such as "social group" with "companies" and words such as "spending time" with "working". A sample question of this scale is "I constantly compare the time I spend working for a company to time I could be working for other companies". This scale was expected to have good reliability with a Cronbach's alpha of at least .80 .

Maximizing tendency in consumer decisions was adapted from the items of the adapted RMS adapted by Newman and colleagues (2017). This 16-item scale was developed by replacing 
words such as "social group" with "stores" and words such as "spending time" with "shopping". A sample question is "I constantly compare the time I spend shopping at a store to time I could be shopping at other stores". The decision to change the wording in this manner was based on the findings of Lia (2011) where it was found that consumer loyalty is lower in those with higher maximizing tendency. However, Lia (2011) focused on consumer loyalty towards television providers. Because many individuals may not have cable or satellite television, items focusing on television providers would not provide a good context for maximizing tendency based on consumer decisions. Instead, the focus was on more general providers of goods and services, with the use of words such as "stores". This scale was expected to have good reliability with a Cronbach's alpha of at least .80 .

A scale for global maximizing tendency was also developed. These items were adapted from the adapted RMS adapted by Newman and colleagues (2017) where words with a relationship context were removed from the items. A sample question is "I constantly compare the time I spend on something to time I could be spending on something else". Developing this scale based on this process allowed consistency across the three developed scales to measure maximizing tendency in specific contexts and without context. This scale was expected to have good reliability with a Cronbach's alpha of at least .80 .

\section{Procedure}

Participants' responses for each item of each scale were aggregated. Cronbach's alphas were estimated from this aggregate data. Cronbach's alphas of at least .80 were used to indicate good reliability. 


\section{CHAPTER IV: METHODS}

\section{Participants}

A sample 460 MTurk workers were given the test items for the current study. This sample was determined as including 10 participants per free parameter is established as a standard for structural equation modeling (Bentler \& Chou, 1987). Participants were not targeted based on demographics of gender or ethnicity and were over the age of 18. This limit on age was chosen as MTurk workers must be at least 18 years of age. Demographic questions were presented in order to determine if the sample avoided targeting based on gender, ethnicity, or age.

\section{Measures}

To measure the construct of maximizing tendency in different contexts, three scales were used. First, the adapted RMS developed by Mikkelson \& Pauley (2013) and adapted by Newman and colleagues (2017) were used to measure maximizing tendency in the context of interpersonal relationship decisions. This 16 -item scale has good reliability with a previously established Cronbach's alpha of .85 (Newman et al., 2017). A sample item from the adapted RMS is "I constantly compare the time I spend with people in my social group to time I could be spending with other people" (Newman et al., 2017). For the items, Likert scales ranging from 1 to 7 were used with 1 being completely disagree and 7 being completely agree. Lastly, item 11 of the RMS which states "Finding friends is difficult because I want to choose the perfect friends for me" was changed to "It is difficult to find the perfect friends for me". This change prevented the item from being double-barreled, containing multiple questions that may have led to two different responses for the single item. 
Maximizing tendency in career decisions was measured with the items of the maximizing tendency in career decisions scale developed through the pilot study. This 16-item scale was expected to have good reliability with a Cronbach's alpha of at least .80 .

Maximizing tendency in consumer decisions was measured with the maximizing tendency in consumer decisions scale developed through the pilot study. This 16-item scale was expected to have good reliability with a Cronbach's alpha of at least .80 .

Global maximizing tendency was measured with the global maximizing tendency scale developed through the pilot study. This 16 -item scale was expected to have good reliability with a Cronbach's alpha of at least .80 .

Regret was measured using the 5-item Regret Scale developed by Schwartz (2002). This scale has shown decent reliability with a previously established Cronbach's alpha of .78 (Purvis et al., 2011). A sample question from the Regret Scale is "Whenever I make a choice, I'm curious about what would have happened if I had chosen differently" (Schwartz, 2002). This scale used Likert Scales ranging from 1 to 7 with 7 being completely agree and 1 being completely disagree (Schwartz, 2002). This scale was developed to correlate regret with maximizing tendency, and replication of this correlation can be seen through the results of a study by Purvis and colleagues (2011). Therefore, using this scale allowed the current study to determine validity of the maximizing tendency measures by correlating overall maximizing tendency with regret measured by the Regret Scale.

\section{Procedure}

Participants were asked to give consent to participate in the study. Next, participants were given the items measuring maximizing tendency in the three different contexts of interpersonal 
relationships, career decisions, and consumer decisions and items measuring maximizing tendency without context. These sets of items were counterbalanced as the order of the sets of items was randomized for each participant. Next, participants were given the MS and the 5 items measuring regret. Participants were then given demographic questions. Following, participants were debriefed and given the contact information of the principal investigators for follow up questions. Participants were compensated $\$ 0.10$ for participating.

\section{Data Analysis}

The responses of the participants were aggregated to test the fits of the hypothesized models. The fits of the hypothesized models were all determined to have good fit with CFI's of .95 or higher, RMSEA's of .05 or lower, NNFI's of .95 or higher, and SRMR's of .05 or lower. To test Hypothesis 1, a confirmatory factor analysis with the items of context specific measures of maximizing tendency and global measure of maximizing tendency in a four-factor model were performed. To test Hypothesis 2, a second confirmatory factor analysis with the items of context specific measures of maximizing tendency and the global measure of maximizing tendency in a single-factor model were performed. Once the model with better fit was determined, Hypothesis 3 was tested through structural equation modeling of the model with paths from the global measure of maximizing tendency towards the specific measures of maximizing tendency. Principal component analysis was performed prior, and the components found were used as item parcels in the structural equation modeling. Using these item parcels in place of the original set of 16 items allowed for parsimony in the models. Using all 16 items would provide information from all 16 loadings that would be unnecessary and difficult to interpret. The sample size of the study, furthermore, would need to be substantially increased for the free parameters introduced 
by these loadings form the original 16 items. If structural equation modeling did not provide good fit, path analysis with composite measures for each measure of maximizing tendency were performed instead. To test Hypothesis 4, structural equation modeling was performed on the model with paths from the global measure of maximizing tendency towards the specific measures of maximizing tendency and paths from the specific measures of maximizing tendency towards regret. To test Hypothesis 5, structural equation modeling was performed on the model with paths from the global measure of maximizing tendency towards the specific measures of maximizing tendency and a path from the global measure of maximizing tendency towards regret. Both structural equation modeling analyses used the item parcels for the maximizing scale items determined from the principal component analysis performed earlier. Further exploratory analyses, lastly, were performed to determine good fitting models in the place of models that did not have good fit. 


\section{CHAPTER V: RESULTS}

All statistical analyses were performed using R Version 3.3.2 and the following $\mathrm{R}$ packages: psych Version 1.6.12, lavaan Version 0.5-22, and plyr Versions 0.5.0 (R Core Team, 2016; Revelle, 2016; Rosseel, 2012; Wickham, 2011).

\section{Descriptive Statistics}

The sample contained 284 participants who identified as female, 169 participants who identified as male, 2 participants who identified as a gender that was not provided in the questionnaire, and 3 participants who chose not to disclose the gender they identified as. The sample also included 38 participants who identified as African American, 40 participants who identified as Asian American, 329 participants who identified as Caucasian, 33 participants who identified as Hispanic or Latino American, 12 participants who identified as a race not provided in the questionnaire, and 8 participants who chose not to disclose the race they identified as. The age of participants in the sample ranged from 18 years to 80 years with a mean age of 35.84 years, a standard deviation of 12.17 years, and a median age of 32 years. Correlations, means, and standard deviations of the items for the Adapted RMS, the Maximizing in Career Decisions Scale, the Maximizing in Consumer Decisions Scale, the Global Maximizing Scale, and Regret Scale can be found in Table 1, Table 2, Table 3, Table 4, and Table 5 respectively. 
Table 1. Correlations between the items of the Adapted Relational Maximizing Scale. Means and standard deviations of the items are also listed.

\begin{tabular}{cccccccccc}
\hline RMS Item & 1 & 2 & 3 & 4 & 5 & 6 & 7 & 8 & 9 \\
\hline Item 1 & - & & & & & & & & \\
Item 2 & 0.65 & - & & & & & & & \\
Item 3 & 0.63 & 0.60 & - & & & & & & \\
Item 4 & 0.45 & 0.52 & 0.39 & - & & & & & \\
Item 5 & 0.58 & 0.56 & 0.55 & 0.35 & - & & & & \\
Item 6 & 0.21 & 0.24 & 0.18 & 0.17 & 0.27 & - & & & \\
Item 7 & 0.19 & 0.25 & 0.20 & 0.23 & 0.27 & 0.54 & - & & \\
Item 8 & 0.21 & 0.24 & 0.10 & 0.20 & 0.27 & 0.57 & 0.51 & - & \\
Item 9 & 0.24 & 0.23 & 0.09 & 0.20 & 0.23 & 0.56 & 0.43 & 0.56 & - \\
Item 10 & 0.30 & 0.27 & 0.24 & 0.22 & 0.29 & 0.46 & 0.50 & 0.49 & 0.45 \\
Item 11 & 0.41 & 0.42 & 0.50 & 0.26 & 0.45 & 0.21 & 0.24 & 0.17 & 0.16 \\
Item 12 & 0.58 & 0.57 & 0.62 & 0.35 & 0.52 & 0.14 & 0.23 & 0.14 & 0.13 \\
Item 13 & 0.50 & 0.45 & 0.56 & 0.29 & 0.45 & 0.14 & 0.20 & 0.12 & 0.10 \\
Item 14 & 0.34 & 0.40 & 0.46 & 0.24 & 0.38 & 0.18 & 0.23 & 0.11 & 0.03 \\
Item 15 & 0.46 & 0.36 & 0.33 & 0.27 & 0.42 & 0.43 & 0.38 & 0.52 & 0.44 \\
Item 16 & 0.25 & 0.20 & 0.19 & 0.19 & 0.26 & 0.44 & 0.44 & 0.44 & 0.41 \\
\hline & & & & & & & & & \\
\hline RMS Item & 10 & 11 & 12 & 13 & 14 & 15 & 16 & $\mathrm{M}$ & $\mathrm{SD}$ \\
\hline Item 1 & & & & & & & & 3.47 & 1.76 \\
Item 2 & & & & & & & & 3.58 & 1.74 \\
Item 3 & & & & & & & & 3.69 & 1.77 \\
Item 4 & & & & & & & & 4.27 & 1.55 \\
Item 5 & & & & & & & & 3.75 & 1.78 \\
Item 6 & & & & & & & & 4.41 & 1.60 \\
Item 7 & & & & & & & & 4.61 & 1.60 \\
Item 8 & & & & & & & & 4.34 & 1.58 \\
Item 9 & & & & & & & & 4.33 & 1.68 \\
Item 10 & - & & & & & & & 4.19 & 1.87 \\
Item 11 & 0.23 & - & & & & & & 3.55 & 1.72 \\
Item 12 & 0.22 & 0.52 & - & & & & & 3.58 & 1.79 \\
Item 13 & 0.22 & 0.61 & 0.59 & - & & & & 4.18 & 1.81 \\
Item 14 & 0.20 & 0.71 & 0.46 & 0.61 & - & & & 4.07 & 1.69 \\
Item 15 & 0.50 & 0.31 & 0.35 & 0.29 & 0.20 & - & & \\
Item 16 & 0.43 & 0.35 & 0.21 & 0.25 & 0.35 & 0.41 & - & 4.78 & 1.66 \\
\hline & & & & & & & & &
\end{tabular}


Table 2. Correlations between the items of the Maximizing in Career Decisions Scale. Means and standard deviations of the items are also listed.

\begin{tabular}{cccccccccc}
\hline Career Item & 1 & 2 & 3 & 4 & 5 & 6 & 7 & 8 & 9 \\
\hline Item 1 & - & & & & & & & & \\
Item 2 & 0.45 & - & & & & & & & \\
Item 3 & 0.53 & 0.40 & - & & & & & & \\
Item 4 & 0.35 & 0.47 & 0.44 & - & & & & & \\
Item 5 & 0.43 & 0.29 & 0.38 & 0.35 & - & & & & \\
Item 6 & 0.27 & 0.21 & 0.11 & 0.23 & 0.24 & - & & & \\
Item 7 & 0.27 & 0.26 & 0.16 & 0.31 & 0.32 & 0.50 & - & & \\
Item 8 & 0.24 & 0.13 & 0.14 & 0.22 & 0.24 & 0.60 & 0.49 & - & \\
Item 9 & 0.17 & 0.13 & 0.08 & 0.22 & 0.21 & 0.58 & 0.49 & 0.53 & - \\
Item 10 & 0.26 & 0.19 & 0.11 & 0.25 & 0.20 & 0.52 & 0.43 & 0.43 & 0.49 \\
Item 11 & 0.40 & 0.30 & 0.47 & 0.26 & 0.33 & 0.10 & 0.11 & 0.02 & 0.00 \\
Item 12 & 0.47 & 0.28 & 0.41 & 0.25 & 0.32 & 0.19 & 0.18 & 0.08 & 0.14 \\
Item 13 & 0.52 & 0.32 & 0.46 & 0.25 & 0.34 & 0.16 & 0.17 & 0.10 & 0.15 \\
Item 14 & 0.50 & 0.34 & 0.45 & 0.29 & 0.32 & 0.12 & 0.13 & 0.06 & 0.07 \\
Item 15 & 0.24 & 0.22 & 0.07 & 0.25 & 0.26 & 0.60 & 0.36 & 0.49 & 0.46 \\
Item 16 & 0.29 & 0.28 & 0.16 & 0.27 & 0.24 & 0.55 & 0.43 & 0.52 & 0.43 \\
\hline & & & & & & & & & \\
\hline Career Item & 10 & 11 & 12 & 13 & 14 & 15 & 16 & $\mathrm{M}$ & $\mathrm{SD}$ \\
\hline Item 1 & & & & & & & & 4.16 & 1.72 \\
Item 2 & & & & & & & & 4.81 & 1.54 \\
Item 3 & & & & & & & & 4.82 & 1.60 \\
Item 4 & & & & & & & & 5.13 & 1.36 \\
Item 5 & & & & & & & & 4.81 & 1.53 \\
Item 6 & & & & & & & & 4.37 & 1.55 \\
Item 7 & & & & & & & & 4.79 & 1.54 \\
Item 8 & & & & & & & & 4.59 & 1.59 \\
Item 9 & & & & & & & & 4.58 & 1.52 \\
Item 10 & - & & & & & & & 4.60 & 1.73 \\
Item 11 & 0.14 & - & & & & & & 4.19 & 1.68 \\
Item 12 & 0.20 & 0.56 & - & & & & & 4.16 & 1.72 \\
Item 13 & 0.17 & 0.62 & 0.64 & - & & & & 4.37 & 1.69 \\
Item 14 & 0.15 & 0.60 & 0.55 & 0.64 & - & & & 4.49 & 1.56 \\
Item 15 & 0.43 & 0.07 & 0.22 & 0.22 & 0.12 & - & & \\
Item 16 & 0.43 & 0.16 & 0.27 & 0.26 & 0.24 & 0.54 & - & 4.43 & 1.61 \\
\hline
\end{tabular}


Table 3. Correlations between the items of the Maximizing in Consumer Decisions Scale. Means and standard deviations of the items are also listed.

\begin{tabular}{cccccccccc}
\hline Consumer Item & 1 & 2 & 3 & 4 & 5 & 6 & 7 & 8 & 9 \\
\hline Item 1 & - & & & & & & & & \\
Item 2 & 0.44 & - & & & & & & & \\
Item 3 & 0.63 & 0.50 & - & & & & & & \\
Item 4 & 0.20 & 0.43 & 0.22 & - & & & & & \\
Item 5 & 0.41 & 0.53 & 0.44 & 0.44 & - & & & & \\
Item 6 & 0.43 & 0.29 & 0.37 & 0.29 & 0.36 & - & & & \\
Item 7 & 0.40 & 0.36 & 0.37 & 0.30 & 0.38 & 0.64 & - & & \\
Item 8 & 0.29 & 0.29 & 0.20 & 0.21 & 0.36 & 0.58 & 0.47 & - & \\
Item 9 & 0.32 & 0.30 & 0.27 & 0.25 & 0.32 & 0.57 & 0.49 & 0.52 & - \\
Item 10 & 0.30 & 0.36 & 0.33 & 0.21 & 0.35 & 0.49 & 0.52 & 0.47 & 0.50 \\
Item 11 & 0.54 & 0.35 & 0.58 & 0.17 & 0.32 & 0.34 & 0.40 & 0.24 & 0.26 \\
Item 12 & 0.56 & 0.36 & 0.60 & 0.13 & 0.29 & 0.35 & 0.37 & 0.20 & 0.26 \\
Item 13 & 0.58 & 0.37 & 0.62 & 0.14 & 0.28 & 0.38 & 0.38 & 0.20 & 0.25 \\
Item 14 & 0.54 & 0.38 & 0.59 & 0.11 & 0.31 & 0.33 & 0.33 & 0.17 & 0.19 \\
Item 15 & 0.33 & 0.23 & 0.30 & 0.18 & 0.35 & 0.55 & 0.45 & 0.43 & 0.46 \\
Item 16 & 0.45 & 0.32 & 0.42 & 0.26 & 0.35 & 0.51 & 0.51 & 0.36 & 0.36 \\
\hline & & & & & & & & & \\
\hline Consumer Item & 10 & 11 & 12 & 13 & 14 & 15 & 16 & $\mathrm{M}$ & $\mathrm{SD}$ \\
\hline Item 1 & & & & & & & & 3.59 & 1.72 \\
Item 2 & & & & & & & & 4.50 & 1.64 \\
Item 3 & & & & & & & & 3.98 & 1.68 \\
Item 4 & & & & & & & & 5.17 & 1.26 \\
Item 5 & & & & & & & & 4.82 & 1.50 \\
Item 6 & & & & & & & & 4.13 & 1.61 \\
Item 7 & & & & & & & & 4.12 & 1.59 \\
Item 8 & & & & & & & & 4.45 & 1.51 \\
Item 9 & & & & & & & & 4.27 & 1.58 \\
Item 10 & - & & & & & & & 3.72 & 1.79 \\
Item 11 & 0.31 & - & & & & & & 3.51 & 1.74 \\
Item 12 & 0.24 & 0.70 & - & & & & & 3.54 & 1.76 \\
Item 13 & 0.29 & 0.73 & 0.79 & - & & & & 3.73 & 1.77 \\
Item 14 & 0.24 & 0.73 & 0.71 & 0.74 & - & & & 4.33 & 1.60 \\
Item 15 & 0.38 & 0.22 & 0.23 & 0.25 & 0.17 & - & -17 \\
Item 16 & 0.35 & 0.43 & 0.41 & 0.42 & 0.37 & 0.46 & - & 4.14 & 1.71 \\
\hline & & & & & & & & &
\end{tabular}


Table 4. Correlations between the items of the Global Maximizing Scale. Means and standard deviations of the items are also listed.

\begin{tabular}{cccccccccc}
\hline Global Item & 1 & 2 & 3 & 4 & 5 & 6 & 7 & 8 & 9 \\
\hline Item 1 & - & & & & & & & & \\
Item 2 & 0.40 & - & & & & & & & \\
Item 3 & 0.54 & 0.42 & - & & & & & & \\
Item 4 & 0.26 & 0.54 & 0.32 & - & & & & & \\
Item 5 & 0.40 & 0.38 & 0.43 & 0.33 & - & & & & \\
Item 6 & 0.22 & 0.25 & 0.10 & 0.18 & 0.23 & - & & & \\
Item 7 & 0.29 & 0.22 & 0.22 & 0.19 & 0.27 & 0.60 & - & & \\
Item 8 & 0.14 & 0.11 & 0.02 & 0.05 & 0.18 & 0.50 & 0.36 & - & \\
Item 9 & 0.17 & 0.14 & 0.05 & 0.13 & 0.17 & 0.51 & 0.44 & 0.48 & - \\
Item 10 & 0.24 & 0.21 & 0.15 & 0.19 & 0.23 & 0.43 & 0.40 & 0.44 & 0.45 \\
Item 11 & 0.43 & 0.35 & 0.49 & 0.18 & 0.29 & 0.14 & 0.24 & 0.07 & 0.08 \\
Item 12 & 0.46 & 0.30 & 0.56 & 0.19 & 0.34 & 0.09 & 0.20 & 0.00 & 0.08 \\
Item 13 & 0.44 & 0.29 & 0.52 & 0.16 & 0.30 & 0.17 & 0.22 & 0.05 & 0.12 \\
Item 14 & 0.45 & 0.34 & 0.47 & 0.20 & 0.31 & 0.17 & 0.22 & 0.13 & 0.07 \\
Item 15 & 0.24 & 0.23 & 0.17 & 0.26 & 0.26 & 0.45 & 0.36 & 0.37 & 0.41 \\
Item 16 & 0.21 & 0.25 & 0.18 & 0.23 & 0.26 & 0.45 & 0.34 & 0.36 & 0.38 \\
\hline & & & & & & & & & \\
\hline Global Item & 10 & 11 & 12 & 13 & 14 & 15 & 16 & $\mathrm{M}$ & $\mathrm{SD}$ \\
\hline Item 1 & & & & & & & & 4.41 & 1.61 \\
Item 2 & & & & & & & & 4.80 & 1.43 \\
Item 3 & & & & & & & & 4.78 & 1.52 \\
Item 4 & & & & & & & & 5.15 & 1.21 \\
Item 5 & & & & & & & & 4.89 & 1.44 \\
Item 6 & & & & & & & & 4.55 & 1.47 \\
Item 7 & & & & & & & & 4.70 & 1.45 \\
Item 8 & & & & & & & & 4.76 & 1.45 \\
Item 9 & & & & & & & & 4.49 & 1.45 \\
Item 10 & - & & & & & & & 4.27 & 1.58 \\
Item 11 & 0.13 & - & & & & & & 4.33 & 1.66 \\
Item 12 & 0.12 & 0.62 & - & & & & & 4.21 & 1.68 \\
Item 13 & 0.11 & 0.62 & 0.70 & - & & & & 4.20 & 1.61 \\
Item 14 & 0.13 & 0.67 & 0.68 & 0.65 & - & & & 4.50 & 1.46 \\
Item 15 & 0.33 & 0.20 & 0.12 & 0.15 & 0.22 & - & & \\
Item 16 & 0.31 & 0.25 & 0.21 & 0.30 & 0.26 & 0.35 & - & 4.82 & 1.34 \\
\hline
\end{tabular}


Table 5. Correlations between the items of the Regret Scale. Means and standard deviations of the items are also listed.

\begin{tabular}{cllllll}
\hline Regret Scale Item & 1 & 2 & 3 & 4 & $\mathrm{M}$ & $\mathrm{SD}$ \\
\hline Item 1 & - & & & & 4.88 & 1.51 \\
Item 2 & .53 & - & & & 4.50 & 1.58 \\
Item 3 & .41 & .44 & - & & 4.00 & 1.73 \\
Item 4 & .59 & .53 & .49 & - & 4.72 & 1.57 \\
Item 5 & .25 & .16 & .13 & .24 & 3.85 & 1.62 \\
\hline
\end{tabular}

\section{Reliability}

The reliability of most scales met the criteria of having a Cronbach's alpha greater than .8. The Adapted Relational Maximizing Scale had an alpha of .89, the Maximizing Scale in the Context of Career Decisions had an alpha of .88, the Maximizing Scale in the Context of Consumer Decisions had an alpha of .91, the Global Maximizing Scale had an alpha of .87, and the Regret Scale had an alpha of .77. Although the Regret Scale did not meet the criteria, the Cronbach's alpha of the Regret scale showed marginal reliability and would still be used going forward.

\section{Exploratory Factor Analyses}

For each exploratory factor analysis, three components were extracted from a principal component analysis. Three factors were chosen as the maximizing tendency scales were each theorized to have three components of alternative search, high standards, and decision difficulty. Three components were also chosen as eigenvalues for these components were greater than 1 . The items with the largest loadings for each component were averaged and used for the item 
parcels in the later analyses. Item 1 of the Maximizing in Career Decisions Scale, however, had two loadings on different components that were almost equal and therefore was included in the same item parcel as items 2 through 5 of the same scale. This decision was made as these items all theoretically corresponded with alternative search in maximizing tendency, and this was theoretically established for the adapted RMS where the three factors of alternative search, high standards, and decision difficulty were determined for the 16 items (Newman, 2017). The loadings of the items for each of the exploratory factor analyses can be found under Table 6 , Table 7, Table 8, and Table 9. Correlations, means, and standard deviations of the item parcels created from the Principal Component Analysis can be found under Table 10. 
Table 6. The loadings for the principal component analysis of the RMS items. Loadings less than 0.30 are suppressed. The largest loading for each item determined the item parcel the item was included in.

\begin{tabular}{cccc}
\hline RMS Item & Component 1 & Component 2 & Component 3 \\
\hline Item 1 & 0.81 & & \\
Item 2 & 0.79 & & 0.41 \\
Item 3 & 0.72 & & \\
Item 4 & 0.66 & & \\
Item 5 & 0.66 & 0.78 & \\
Item 6 & & 0.71 & \\
Item 7 & & 0.81 & \\
Item 8 & & 0.76 & 0.80 \\
Item 9 & & 0.69 & 0.46 \\
Item 10 & & 0.86 \\
Item 11 & & & \\
Item 12 & 0.65 & & 0.39 \\
Item 13 & 0.43 & 0.61 & \\
Item 14 & & 0.65 & \\
Item 15 & 0.41 & & \\
Item 16 & & & \\
\hline
\end{tabular}


Table 7. The loadings for the principal component analysis of the Maximizing in Career

Decisions Scale items. Loadings less than 0.30 are suppressed. The largest loading for each item determined the item parcel the item was included in. Item 1, however, was included in the item parcel that corresponded with the highest loadings on Component 3.

\begin{tabular}{cccc}
\hline Maximizing in Career Item & Component 1 & Component 2 & Component 3 \\
\hline Item 1 & 0.52 & & 0.51 \\
Item 2 & & & 0.72 \\
Item 3 & 0.45 & & 0.63 \\
Item 4 & & & 0.77 \\
Item 5 & & 0.83 & 0.51 \\
Item 6 & & 0.64 & \\
Item 7 & & 0.77 & \\
Item 8 & & 0.77 & \\
Item 9 & & 0.69 & \\
Item 10 & & & \\
Item 11 & & & \\
Item 12 & 0.79 & & \\
Item 13 & 0.80 & & \\
Item 14 & 0.84 & & \\
Item 15 & 0.78 & & \\
Item 16 & & & \\
\hline
\end{tabular}


Table 8. The loadings for the principal component analysis of the Maximizing in Consumer Decisions Scale items. Loadings less than 0.30 are suppressed. The largest loading for each item determined the item parcel the item was included in.

\begin{tabular}{cccc}
\hline Maximizing in Consumer Item & Component 1 & Component 2 & Component 3 \\
\hline Item 1 & 0.65 & & \\
Item 2 & 0.34 & & 0.73 \\
Item 3 & 0.71 & & 0.35 \\
Item 4 & & 0.30 & 0.79 \\
Item 5 & & 0.80 & \\
Item 6 & & 0.71 \\
Item 7 & & 0.75 & \\
Item 8 & & 0.74 & \\
Item 9 & & 0.66 & \\
Item 10 & 0.83 & & \\
Item 11 & 0.86 & & \\
Item 12 & 0.88 & & \\
Item 13 & 0.86 & & \\
Item 14 & & 0.71 & \\
Item 15 & 0.40 & 0.54 & \\
Item 16 & &
\end{tabular}


Table 9. The loadings for the principal component analysis of the Global Maximizing Scale items. Loadings less than 0.30 are suppressed. The largest loading for each item determined the item parcel the item was included in.

\begin{tabular}{cccc}
\hline Global Item & Component 1 & Component 2 & Component 3 \\
\hline Item 1 & 0.54 & & 0.40 \\
Item 2 & & & 0.77 \\
Item 3 & 0.62 & & 0.47 \\
Item 4 & & 0.80 & 0.83 \\
Item 5 & 0.30 & 0.68 & \\
Item 6 & & 0.75 & \\
Item 7 & & 0.76 & \\
Item 8 & & 0.65 & \\
Item 9 & & & \\
Item 10 & & & \\
Item 11 & 0.80 & & \\
Item 12 & 0.86 & 0.61 & \\
Item 13 & 0.85 & 0.58 & \\
Item 14 & 0.83 & & \\
Item 15 & & & \\
Item 16 & & & \\
\hline
\end{tabular}


Table 10. Correlations between the item parcels created from the principal component analyses. Columns represent item parcels of the same scale of the respective row. Means and standard deviations are also displayed.

\begin{tabular}{cccccc}
\hline Item Parcel & 1 & 2 & 3 & M & SD \\
\hline RMS Item Parcel 1 & - & & & 3.72 & 1.34 \\
RMS Item Parcel 2 & 0.41 & - & & 4.43 & 1.20 \\
RMS Item Parcel 3 & 0.63 & 0.32 & - & 3.98 & 1.59 \\
Career Decisions Item Parcel 1 & - & & & 4.75 & 1.13 \\
Career Decisions Item Parcel 2 & 0.39 & - & & 4.53 & 1.17 \\
Career Decisions Item Parcel 3 & 0.61 & 0.23 & - & 4.33 & 1.43 \\
Consumer Decisions Item Parcel 1 & - & & & 3.68 & 1.45 \\
Consumer Decisions Item Parcel 2 & 0.50 & - & & 4.24 & 1.19 \\
Consumer Decisions Item Parcel 3 & 0.46 & 0.51 & - & 4.83 & 1.18 \\
Consumer Decisions Item Parcel 1 & - & & & 4.37 & 1.27 \\
Consumer Decisions Item Parcel 2 & 0.28 & - & & 4.62 & 1.00 \\
Consumer Decisions Item Parcel 3 & 0.50 & 0.37 & - & 4.95 & 1.06 \\
\hline
\end{tabular}

\section{Confirmatory Factor Analyses}

The four factor model with the items loading to their respective factors did not have good fit, $\mathrm{CFI}=0.53, \mathrm{NNFI}=0.51, \mathrm{RMSEA}=0.09, \mathrm{SRMR}=0.21$. Modification indices were investigated to determine if any parameters could be added to the model for better fit. After adding all correlations between the latent constructs, the four factor model with the items loading to their respective factors did not have good fit, $\mathrm{CFI}=0.57, \mathrm{NNFI}=0.55, \mathrm{RMSEA}=0.09$, $\mathrm{SRMR}=0.11$. The one factor model with all items loading to the same factor did not have good fit, $\mathrm{CFI}=0.42, \mathrm{NNFI}=0.40, \mathrm{RMSEA}=0.10, \mathrm{SRMR}=0.12$. Modification indices were not investigated as no parameters could have been added to the model without leading to an 
ambiguous identification status of the model. The three factor model without the global maximizing scale items and the remaining items loading to their respective factors did not have good fit, $\mathrm{CFI}=0.57, \mathrm{NNFI}=0.55, \mathrm{RMSEA}=0.10, \mathrm{SRMR}=0.20$. Modification indices were investigated to determine if any parameters could be added to the model for better fit. After adding all correlations between the latent constructs, the three factor model without the global maximizing scale items and the remaining items loading to their respective factors did not have good fit, $\mathrm{CFI}=0.60, \mathrm{NNFI}=0.58, \mathrm{RMSEA}=0.10, \mathrm{SRMR}=0.11$. The best fitting model, the three factor model without the global maximizing scale items, with parameter estimates can be found under Table 11. Although none of the models had good fit, the structural equation modeling and path analyses were still performed. 
Table 11.Standardized estimates for the lambdas and theta-deltas for the confirmatory factor analysis of the three-factor model.

\begin{tabular}{|c|c|c|c|c|}
\hline Item & $\begin{array}{c}\text { Relationship } \\
\text { Decisions }\end{array}$ & $\begin{array}{c}\text { Career } \\
\text { Decisions } \\
\end{array}$ & $\begin{array}{l}\text { Consumer } \\
\text { Decisions }\end{array}$ & $\Theta_{\delta}$ \\
\hline RMS Item 1 & 1.00 & & & 1.34 \\
\hline RMS Item 2 & 0.97 & & & 1.37 \\
\hline RMS Item 3 & 0.99 & & & 1.41 \\
\hline RMS Item 4 & 0.60 & & & 1.75 \\
\hline RMS Item 5 & 0.95 & & & 1.57 \\
\hline RMS Item 6 & 0.48 & & & 2.13 \\
\hline RMS Item 7 & 0.51 & & & 2.08 \\
\hline RMS Item 8 & 0.46 & & & 2.10 \\
\hline RMS Item 9 & 0.42 & & & 2.20 \\
\hline RMS Item 10 & 0.58 & & & 2.21 \\
\hline RMS Item 11 & 0.94 & & & 1.93 \\
\hline RMS Item 12 & 0.94 & & & 1.38 \\
\hline RMS Item 13 & 0.92 & & & 1.71 \\
\hline RMS Item 14 & 0.82 & & & 2.07 \\
\hline RMS Item 15 & 0.72 & & & 1.92 \\
\hline RMS Item 16 & 0.55 & & & 2.21 \\
\hline Career Decisions Item 1 & & 1.00 & & 1.55 \\
\hline Career Decisions Item 2 & & 0.68 & & 1.69 \\
\hline Career Decisions Item 3 & & 0.77 & & 1.70 \\
\hline Career Decisions Item 4 & & 0.60 & & 1.34 \\
\hline Career Decisions Item 5 & & 0.70 & & 1.64 \\
\hline Career Decisions Item 6 & & 0.68 & & 1.73 \\
\hline Career Decisions Item 7 & & 0.64 & & 1.77 \\
\hline Career Decisions Item 8 & & 0.59 & & 2.03 \\
\hline Career Decisions Item 9 & & 0.55 & & 1.86 \\
\hline Career Decisions Item 10 & & 0.61 & & 1.75 \\
\hline Career Decisions Item 11 & & 0.82 & & 2.02 \\
\hline Career Decisions Item 12 & & 0.89 & & 1.69 \\
\hline Career Decisions Item 13 & & 0.96 & & 1.63 \\
\hline Career Decisions Item 14 & & 0.88 & & 1.74 \\
\hline Career Decisions Item 15 & & 0.65 & & 1.84 \\
\hline
\end{tabular}

Table is continued on the next page 


\begin{tabular}{ccccc}
\hline Item & $\begin{array}{c}\text { Relationship } \\
\text { Decisions }\end{array}$ & $\begin{array}{c}\text { Career } \\
\text { Decisions }\end{array}$ & $\begin{array}{c}\text { Consumer } \\
\text { Decisions }\end{array}$ & $\Theta \delta$ \\
\hline Career Decisions Item 16 & 0.75 & & 1.76 \\
Consumer Decisions Item 1 & & 1.00 & 1.40 \\
Consumer Decisions Item 2 & & 0.71 & 1.87 \\
Consumer Decisions Item 3 & & 1.00 & 1.24 \\
Consumer Decisions Item 4 & & 0.30 & 1.43 \\
Consumer Decisions Item 5 & & 0.60 & 1.65 \\
Consumer Decisions Item 6 & & 0.75 & 1.69 \\
Consumer Decisions Item 7 & & 0.75 & 1.63 \\
Consumer Decisions Item 8 & & 0.50 & 1.88 \\
Consumer Decisions Item 9 & & 0.57 & 1.96 \\
Consumer Decisions Item 10 & & 0.60 & 1.94 \\
Consumer Decisions Item 11 & & 1.09 & 1.13 \\
Consumer Decisions Item 12 & & 1.10 & 1.13 \\
Consumer Decisions Item 13 & & 1.14 & 1.03 \\
Consumer Decisions Item 14 & & 1.08 & 1.29 \\
Consumer Decisions Item 15 & & 0.55 & 2.05 \\
Consumer Decisions Item 16 & & 0.82 & 1.87 \\
\hline
\end{tabular}

\section{Structural Equation Modeling and Path Analyses}

The model for Hypothesis 3 was tested with structural equation modeling and did not have good fit, $\mathrm{CFI}=0.68, \mathrm{NNFI}=0.59, \mathrm{RMSEA}=0.18, \mathrm{SRMR}=0.11$. A path analysis of the model for Hypothesis 3 without latent variables and with average measures of each construct instead was performed, and the model did not have good fit, $\mathrm{CFI}=0.87, \mathrm{NNFI}=0.75, \mathrm{RMSEA}$ $=0.25, \mathrm{SRMR}=0.10$. The model with parameter estimates can be found under Figure 5 . Although neither of the models had good fit, the next structural equation modeling and path analyses were still performed. 


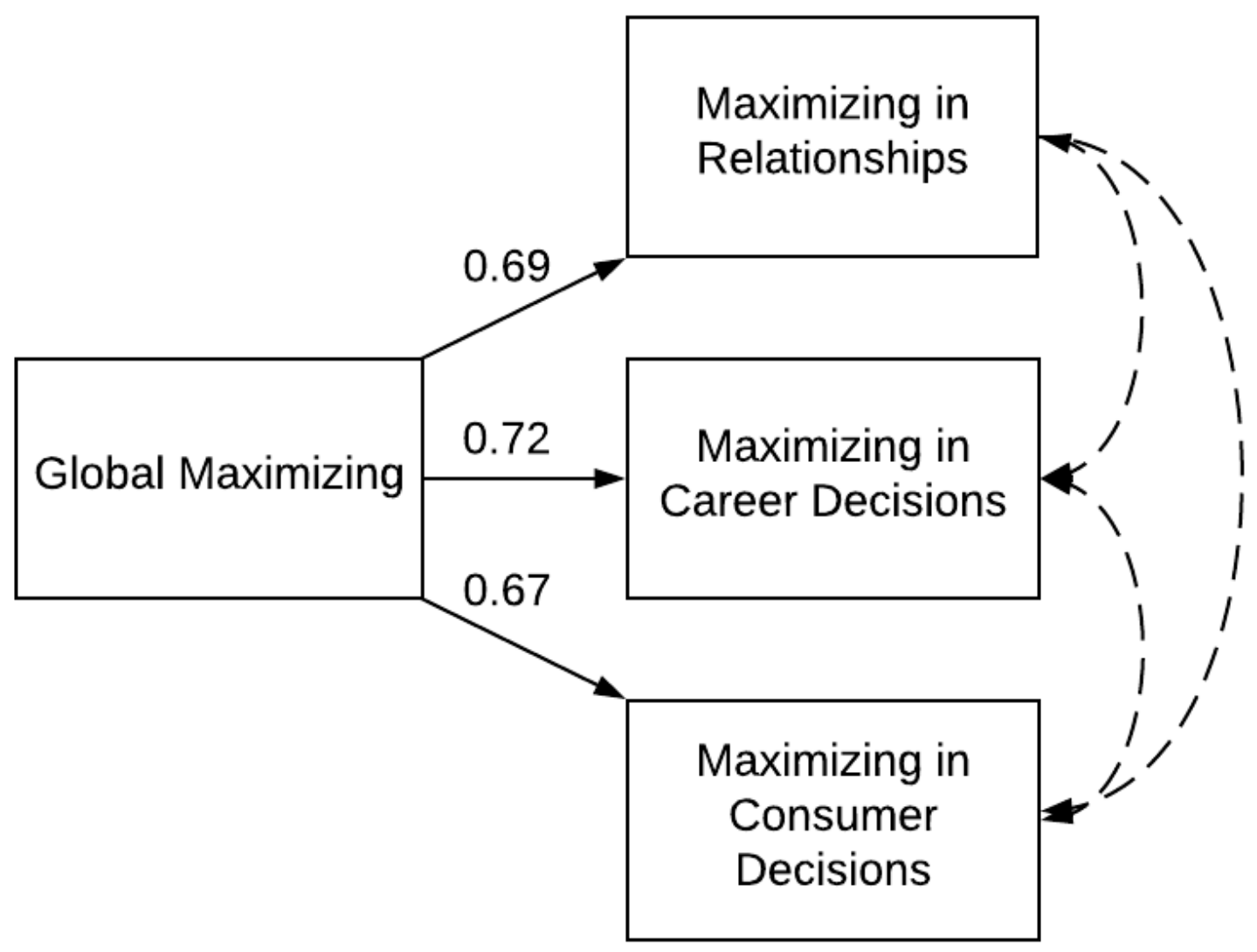

Figure 5. The model for hypothesis three tested with path analysis. Standard estimates for the path are included, $\mathrm{CFI}=0.87, \mathrm{NNFI}=0.75, \mathrm{RMSEA}=0.25, \mathrm{SRMR}=0.10$.

The model for Hypothesis 4 was tested with structural equation modeling and did not have good fit, $\mathrm{CFI}=0.69, \mathrm{NNFI}=0.63, \mathrm{RMSEA}=0.14, \mathrm{SRMR}=0.12$. The model for Hypothesis 5 was tested with structural equation modeling and did not have good fit, $\mathrm{CFI}=0.70$, $\mathrm{NNFI}=0.64, \mathrm{RMSEA}=0.14, \mathrm{SRMR}=0.12$. The model for Hypothesis 4 with the addition of 
the path from Global Maximizing to Regret included in the Hypothesis 5 model was tested with structural equation modeling and did not have good fit, $\mathrm{CFI}=0.70, \mathrm{NNFI}=0.64, \mathrm{RMSEA}=$ $0.14, \mathrm{SRMR}=0.12$.

Since none of the models tested using structural equation modeling had good fit, three path analyses were performed to test the same models without latent variables and with average measures of each construct. The model for Hypothesis 4 was tested with path analysis and did not have good fit, $\mathrm{CFI}=0.85, \mathrm{NNFI}=0.62, \mathrm{RMSEA}=0.25, \mathrm{SRMR}=0.09$. The model for Hypothesis 5 was tested with path analysis and did not have good fit, CFI $=0.89$, NNFI $=0.81$, RMSEA $=0.18, \mathrm{SRMR}=0.08$. The model for Hypothesis 4 with the addition of the path from Global Maximizing Tendency to Regret included in the model for Hypothesis 5 was tested with path analysis and did not have good fit, $\mathrm{CFI}=0.89, \mathrm{NNFI}=0.64, \mathrm{RMSEA}=0.25, \mathrm{SRMR}=$ 0.08. The best fitting model with parameter estimates can be found under Figure 6 . 


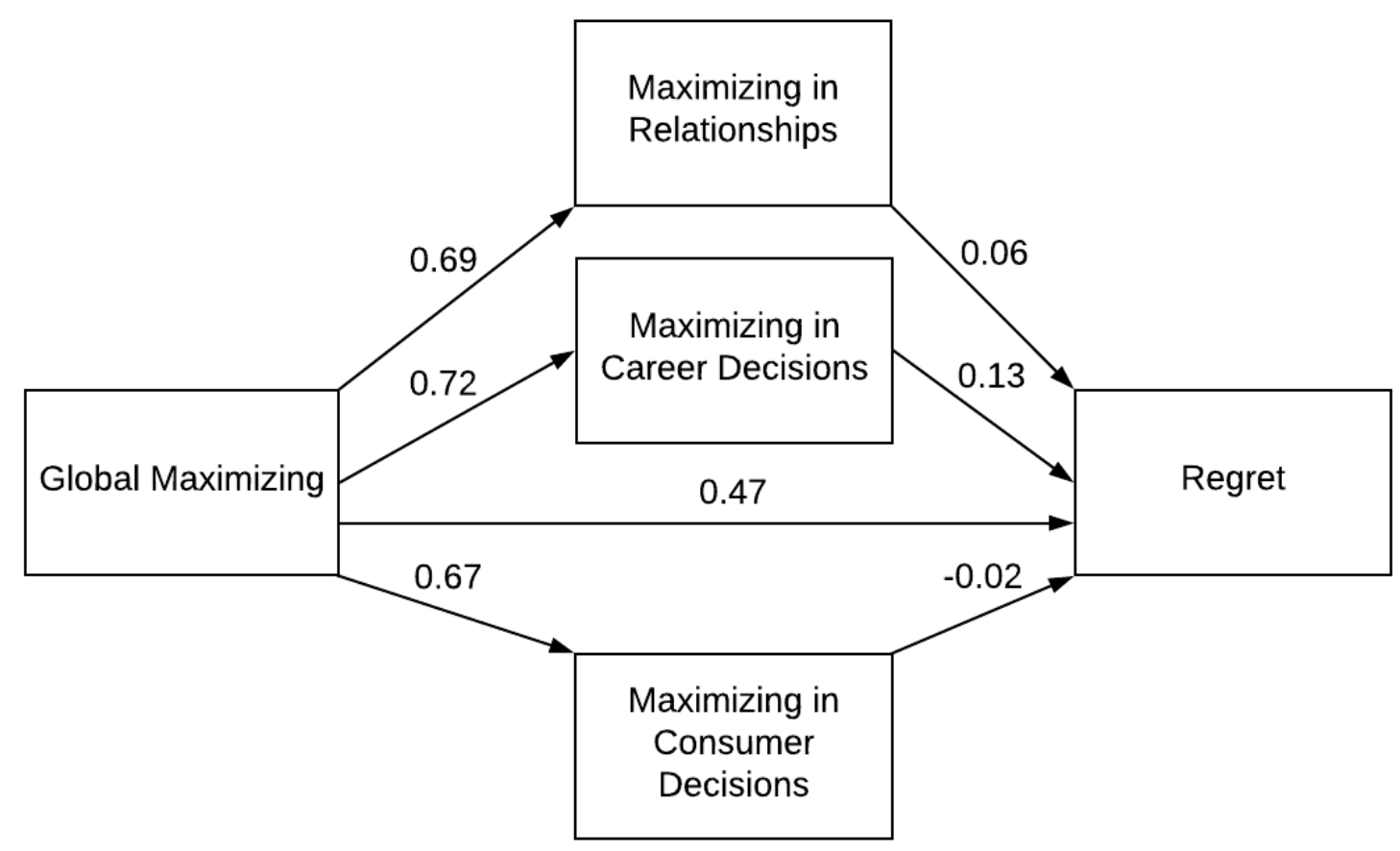

Figure 6. The model tested for Hypotheses 4 and 5 with all paths in the model. Standardized estimates for the paths are included, $\mathrm{CFI}=0.89, \mathrm{NNFI}=0.64, \mathrm{RMSEA}=0.25, \mathrm{SRMR}=0.08$.

\section{Exploratory Analyses}

Since no models had good fit, exploratory analyses were performed for all hypotheses and included confirmatory factor analyses, structural equation modeling, and path analyses. The exploratory analyses were performed based on two underlying theories. The first theory was that the exploratory factor analyses should be disregarded, and the item parcels used should contain the averages of the alternative search, high standards, and decision difficulty items identified by the original Relational Maximizing Scale. The second theory was that groups of items should be 
tested in separate models that only contained constructs related to the alternative search, high standards, or decision difficulty items.

None of the models using item parcels containing averages of alternative search items, high standards items, and decision difficulty items had good fit when tested with structural equation modeling and path analysis. Models with good fit, however, were found using only the high standards items for each maximizing construct. The three factor model for the high standards items with all correlations between latent constructs was tested with confirmatory factor analysis and had good fit, $\mathrm{CFI}=0.97, \mathrm{NNFI}=0.96, \mathrm{RMSEA}=0.05, \mathrm{SRMR}=0.04$. The parameter estimates for the three factor model can be found under Table 12. The model testing Hypothesis 4 for the high standards items was tested with path analysis and had marginal fit, CFI $=0.89, \mathrm{NNFI}=0.82, \mathrm{RMSEA}=0.15, \mathrm{SRMR}=0.07$. The model testing Hypothesis 4 for the high standards items with parameter estimates can be found under Figure 7. 
Table 12. Parameter estimates for the three-factor model using the high standards items.

\begin{tabular}{ccccc}
\hline & \multicolumn{3}{c}{$\lambda$} & \\
\cline { 2 - 4 } Item & $\begin{array}{c}\text { Relationship } \\
\text { Decisions }\end{array}$ & $\begin{array}{c}\text { Career } \\
\text { Decisions }\end{array}$ & $\begin{array}{c}\text { Consumer } \\
\text { Decisions }\end{array}$ & $\Theta \delta$ \\
\hline RMS Item 6 & 1.00 & & & 1.06 \\
RMS Item 7 & 0.89 & & & 1.36 \\
RMS Item 8 & 0.98 & & & 1.04 \\
RMS Item 9 & 0.92 & & & 1.25 \\
RMS Item 10 & 0.89 & & & 1.62 \\
Career Decisions Item 6 & & 1.00 & & 0.85 \\
Career Decisions Item 7 & & 0.8 & & 1.35 \\
Career Decisions Item 8 & & 0.93 & & 1.18 \\
Career Decisions Item 9 & & 0.90 & & 1.05 \\
Career Decisions Item 10 & & 0.78 & & 1.33 \\
Consumer Decisions Item 6 & & & 1.00 & 0.86 \\
Consumer Decisions Item 7 & & & 0.90 & 1.12 \\
Consumer Decisions Item 8 & & & 0.79 & 1.17 \\
Consumer Decisions Item 9 & & & 0.84 & 1.24 \\
Consumer Decisions Item 10 & & & 0.79 & 1.43 \\
\hline
\end{tabular}




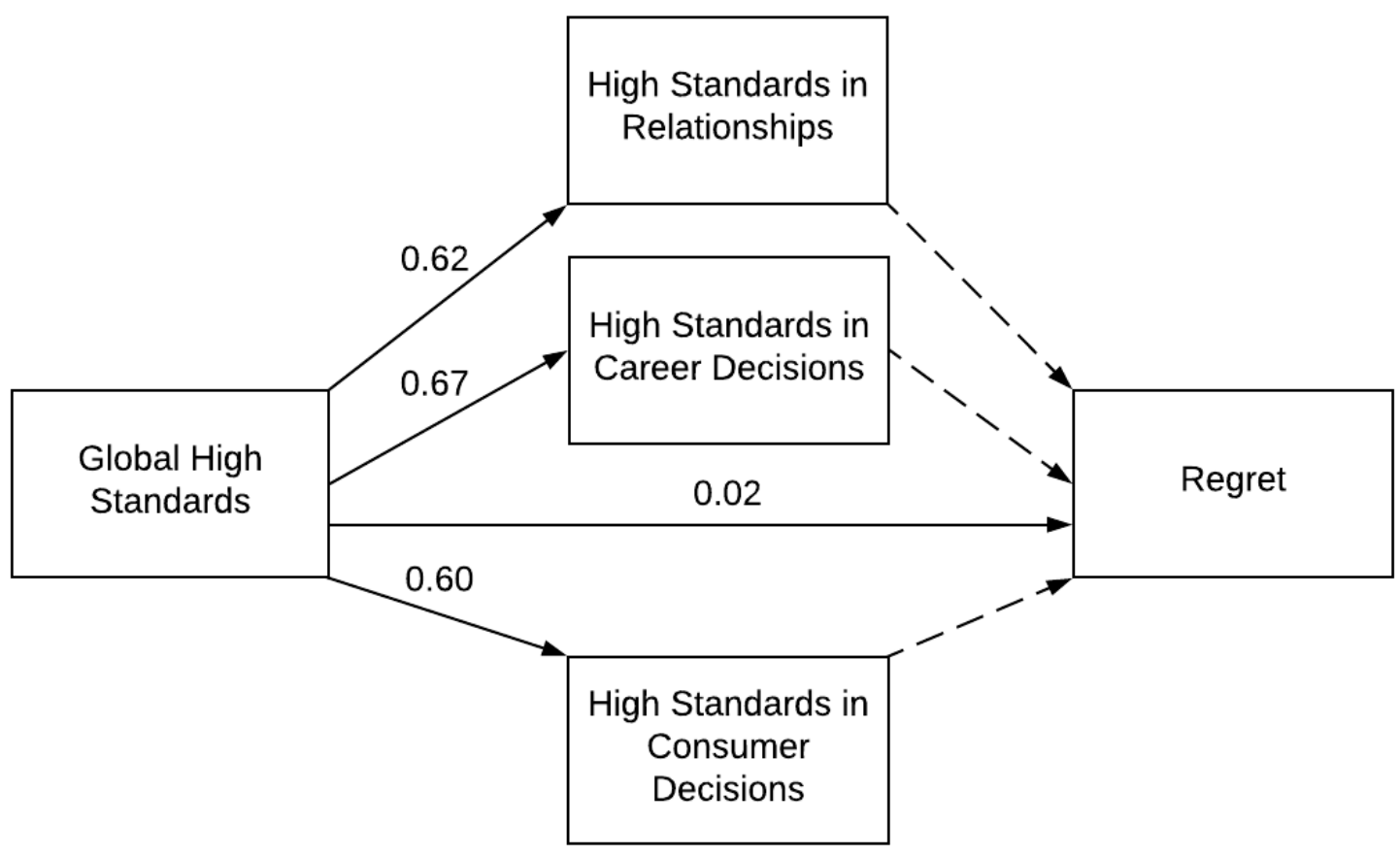

Figure 7. The model testing Hypothesis 4 using only the high standard measures of the maximizing scales. Dashed lines indicate paths set to 0. Parameter estimates for the remaining paths are included, $\mathrm{CFI}=0.89, \mathrm{NNFI}=0.82, \mathrm{RMSEA}=0.15, \mathrm{SRMR}=0.07$. 


\section{CHAPTER VI: DISCUSSION}

The purpose of the current study was to determine if the underlying mechanisms of maximizing tendency were consistent or varied across situations making them global or specific respectively. Results revealed inconclusive results about the consistency of these underlying mechanisms for the definition of maximizing tendency used by Swartz (2002). Exploratory analyses, however, revealed that looking at high standards, a theoretical factor of maximizing tendency, could be beneficial in determining the consistency of the underlying mechanisms of maximizing tendency.

The definition of maximizing tendency used by Swartz (2002), first of all, was the definition of maximizing tendency used in this study as the Relational Maximizing Scale developed by Newman (2017) that was used and adapted for this study also used this definition of maximizing tendency as seen by its factors of alternative search, high standards, and decision difficulty. Regret, furthermore, would be analyzed as an outcome variable in the current study, and previous studies have found the definition of maximizing tendency used by Swartz (2002) to be correlated with regret. The results of the current study contradicted the findings of Swartz (2002) and Newman (2017) and did not find global and specific measures of maximizing tendency to predict regret significantly. The study, however, did find measures of high standards to predict regret marginally. The fit of the models using high standards in place of maximizing tendency as a whole, consequently, support the findings of Diab and colleagues (2008) where it was theorized that maximizing tendency should not include decision difficulty as a factor.

Caution, however, should be taken when interpreting the exploratory findings as these findings were found while looking at all three factors of maximizing tendency at once as 
opposed to focusing on one factor at a time. For these findings to be a priori, a follow up study would need to replicate the study with only the high standard items administered to participants. Replication, in fact, may lead to significant findings where only marginal findings were found.

It was also found that the scales created were not mutually exclusive. Correlations between latent constructs were originally omitted as it was theorized that the created scales would have minimal to no overlap. However, the confirmatory factor analyses showed that models with correlated latent variables had better fit. This finding does not support the theory that the scales created were not correlated. This finding also supports that maximizing tendency may not differ between different contexts as maximizing tendency of different contexts were all correlated in the better fitting models. No models with good fit, however, were found for the a priori confirmatory factor analyses. This finding, therefore, only provides marginal support for maximizing tendency being consistent across different contexts.

It should also be noted that a priori analyses and exploratory analyses did not reveal any models with good fit for the model in Hypothesis 3. Although the scales had good face validity and good reliability, they did not have good concurrent validity with each other. This scenario could lead to several possible explanations. These explanations included that the test items were not measuring maximizing tendency in different contexts or lack of context. These explanations also include that the context specific measures of maximizing tendency were not encompassing the same underlying mechanism of maximizing tendency as the global measures of maximizing tendency. The latter of these explanations is more likely as the Relational Maximizing Scale items had been tested before and showed concurrent reliability with regret (Newman, 2017). The model in Hypothesis 4, furthermore, had the best fit of the models relating maximizing tendency 
with regret also showing that the different maximizing scales did not have the same underlying mechanisms when measured in specific contexts or globally. The exploratory analyses, lastly, also showed the model in Hypothesis 4 had marginal fit when only high standards items were used, further supporting the differences in the underlying mechanisms of context specific and global maximizing.

\section{Limitations}

As stated earlier, using different maximizing scales such as the MTS for adaptations of maximizing scales in different contexts could have led to different findings. The current study focused on the MS as the findings were to be used to find relations between maximizing tendency in different contexts and regret. Looking at relations with different outcomes of maximizing tendency, however, could be beneficial, and using different maximizing scales that correlate with these different outcome variables would make sense. The new scales created could also be uncorrelated, thus allowing the theory that maximizing tendencies across different contexts are uncorrelated to be true.

As with most studies, the sample size could have also been increased. Although the sample size was large enough theoretically for the models in the current study, a larger sample size could have allowed the item parcel method to be bypassed, and insignificant paths between these items and the latent constructs in the structural equation modeling analyses could have been eliminated resulting in different fitting models.

The reliability of the regret scale, furthermore, could also have been increased. The lower reliability could have been a result of fatigue from participants as this scale was administered last in the study. The reliability scale was also more sensitive to response bias as the regret scale 
contained a reversed scored item that could have greatly hurt reliability if responses bias occurred. It is also possible that the five item scale was not comprehensive enough for the construct of regret and required more items to truly capture the construct of regret. The first and second of these problem could have been solved with a survey design with less questions for the other constructs in the study, a break in between the items for participants to rest, or greater compensation that could motivate participants leading to less fatigue and more truthful responses. As for the third problem, it could be addressed with creating a new scale for regret. This third problem, however, was not as likely as the others due to the validity and reliability of the regret scale in previous maximizing tendency studies.

The design of the study, lastly, could have been longitudinal. This would allow maximizing tendency in different contexts to be measured at different times. This longitudinal design would then allow more modification indices to be investigated when determining parameters to add for better fitting models. For most of the models in the current study, modification indices were ignored as many parameters that led to maximizing tendency in one context predicting maximizing tendency in another did not make sense to be added to the model. Measures of maximizing tendency in different contexts at different times, however, would have allowed parameters that led to maximizing tendency at an earlier time predicting maximizing tendency at a later time to makes sense. The construct of regret, lastly, could actually be predicted by maximizing tendency if the regret scale was administered at a later time after administering the maximizing tendency scales. It should be noted that, with this longitudinal design, correlations between the contexts should still be avoided. These correlations may lead to putting model identification in question. The context specific measures, furthermore, may have 
underlying mechanisms that predict other constructs in the model differently, and it is not clear how predicting outcomes from these underlying mechanisms would be affected when correlations are added to the model. Splitting up the context specific measures to further investigate these underlying mechanisms would need to be done before considering adding correlations between the context specific measures that would not lead to models with unclear identification statuses.

\section{Future Directions}

The takeaway from the results of this study is that maximizing tendency could be divided further into its different factors in different contexts and global contexts, and doing so could reduce inconsistent findings. Future studies could continue the investigation of maximizing tendency in different contexts and global contexts with different maximizing scales. Specifically, replicating the current study with scales that do not contain decision difficulty such as adaptations of the MTS may provide good fitting models that can better determine the underlying mechanisms of maximizing tendency.

Longitudinal designs could also be utilized to determine if maximizing tendency in different contexts leads to different outcomes such as regret or eudaimonic well-being. Regret could also be measured at different times to determine if experiences of regret cause high maximizing tendency for individuals, leading to a bi-directional relation between maximizing tendency and regret.

High standard items could also be administered separate from the other maximizing tendency items to see if the same models have good fit with latent constructs of high standards as opposed to latent constructs of high standards in the context of maximizing tendency. Better 
understanding the factors of maximizing tendency may also clear up the inconsistent definition of maximizing tendency. With a clear definition, future studies could determine if maximizing tendency truly correlates with regret or other constructs with positive connotations. 


\section{REFERENCES}

Bentler, P. M., \& Chou, C. P. (1987). Practical issues in structural modeling. Sociological Methods \& Research, 16(1), 78-117.

Bruine de Bruin, W., Dombrovski, A. Y., Parker, A. M., \& Szanto, K. (2016). Late-life depression, suicidal ideation, and attempted suicide: The role of individual differences in maximizing, regret, and negative decision outcomes. Journal of behavioral decision making, 29(4), 363-371.

Carter, T. J., \& Gilovich, T. (2010). The relative relativity of material and experiential purchases. Journal of personality and social psychology, 98(1), 146.

Cheek, N. N., \& Schwartz, B. (2016). On the meaning and measurement of maximization. Judgment and Decision making, 11(2), 126.

Chowdhury, T. G., Ratneshwar, S., \& Mohanty, P. (2009). The time-harried shopper: Exploring the differences between maximizers and satisficers. Marketing Letters, 20(2), 155-167.

Diab, D. L., Gillespie, M. A., \& Highhouse, S. (2008). Are maximizers really unhappy? The measurement of maximizing tendency. Judgment and Decision Making, 3(5), 364.

Giacopelli, N. M., Simpson, K. M., Dalal, R. S., Randolph, K. L., \& Holland, S. J. (2013). Maximizing as a predictor of job satisfaction and performance: A tale of three scales. Judgment and Decision Making, 8(4), 448.

Iyengar, S. S., Wells, R. E., \& Schwartz, B. (2006). Doing better but feeling worse: Looking for the "best" job undermines satisfaction. Psychological Science, 17(2), 143-150. 
Kokkoris, M. D. (2016). Revisiting the relationship between maximizing and well-being: an investigation of eudaimonic well-being. Personality and Individual Differences, 99, 174178. doi: 10.1016/j.paid.2016.04.099.

Lai, L. (2010). Maximizing without difficulty: A modified maximizing scale and its correlates. Judgment and Decision Making, 5(3), 164.

Lai, L. (2011). Maximizing and customer loyalty: Are maximizers less loyal?. Judgment and Decision Making, 6(4), 307.

Leach, J. K., \& Patall, E. A. (2013). Maximizing and counterfactual thinking in academic major decision making. Journal of Career Assessment, 21(3), 414-429.

Mao, W. (2016). When one desires too much of a good thing: The compromise effect under maximizing tendencies. Journal of Consumer Psychology, 26(1), 66-80.

Mikkelson, A. C., \& Pauley, P. M. (2013). Maximizing relationship possibilities: Relational maximization in romantic relationships. The Journal of social psychology, 153(4), 467485.

Misuraca, R., Faraci, P., Gangemi, A., Carmeci, F. A., \& Miceli, S. (2015). The Decision Making Tendency Inventory: A new measure to assess maximizing, satisficing, and minimizing. Personality and Individual Differences, 85, 111-116.

Nenkov, G., Morrin, M., Ward, A., Schwartz, B., \& Hulland, J. (2008). A short form of the maximization scale: Factor structure, reliability and validity studies. Judgment and Decision Making, 3, 371-388. 
Newman, D. B., Schug, J., Yuki, M., Yamada, J., \& Nezlek, J. B. (2017). The Negative Consequences of Maximizing in Friendship Selection. Journal of Personality and Social Psychology, Advance online publication. http://dx.doi.org/10.1037/pspp0000141

Oishi, S., Tsutsui, Y., Eggleston, C., \& Galinha, I. C. (2014). Are maximizers unhappier than satisficers? A comparison between Japan and the USA. Journal of Research in Personality, 49, 14-20.

Purvis, A., Howell, R. T., \& Iyer, R. (2011). Exploring the role of personality in the relationship between maximization and well-being. Personality and Individual Differences, 50(3), $370-375$.

R Core Team (2016). R: A language and environment for statistical computing. R Foundation for Statistical Computing, Vienna, Austria. URL https://www.R-project.org/.

Revelle, W. (2016) psych: Procedures for Personality and Psychological Research, Northwestern University, Evanston, Illinois, USA, https://CRAN.R-project.org/package=psych

Rim, H. B., Turner, B. M., Betz, N. E., \& Nygren, T. E. (2011). Studies of the dimensionality, correlates, and meaning of measures of the maximizing tendency. Judgment and Decision Making, 6(6), 565.

Rim, H. B. (2017). Impacts of Maximizing Tendencies on Experience-Based Decisions. Psychological Reports, 120(3), 460-474.

Rosseel, Y. (2012). lavaan: An R Package for Structural Equation Modeling. Journal of Statistical Software, 48(2), 1-36. URL http://www.jstatsoft.org/v48/i02/. 
Schwartz, B., Ward, A., Monterosso, J., Lyubomirsky, S., White, K., \& Lehman, D. R. (2002). Maximizing versus satisficing: happiness is a matter of choice. Journal of personality and social psychology, 83(5), 1178.

Weinhardt, J. M., Morse, B. J., \& Chimeli, J. (2012). An item response theory and factor analytic examination of two prominent maximizing tendency scales. Judgment and Decision Making, 7(5), 644.

Wickham, H. (2011). The Split-Apply-Combine Strategy for Data Analysis. Journal of Statistical Software, 40(1), 1-29. URL http://www.jstatsoft.org/v40/i01/. 